TI 2006-052/3

Tinbergen Institute Discussion Paper

A Collective Household Model of
Time Allocation -

A Comparison of Native Dutch and Immigrant Households in the Netherlands

Chris van Klaveren

Bernard van Praag*

Henriëtte Maassen van den Brink

SCHOLAR, University of Amsterdam.

IZA, DIW, CESifo, and Honorary Fellow Tinbergen Institute. 


\section{Tinbergen Institute}

The Tinbergen Institute is the institute for economic research of the Erasmus Universiteit Rotterdam, Universiteit van Amsterdam, and Vrije Universiteit Amsterdam.

Tinbergen Institute Amsterdam

Roetersstraat 31

1018 WB Amsterdam

The Netherlands

Tel.: $\quad+31(0) 205513500$

Fax: $\quad+31(0) 205513555$

Tinbergen Institute Rotterdam

Burg. Oudlaan 50

3062 PA Rotterdam

The Netherlands

Tel.: $\quad+31(0) 104088900$

Fax: $\quad+31(0) 104089031$

Most TI discussion papers can be downloaded at http:/ /www.tinbergen.nl. 


\title{
A Collective Household Model of Time Allocation A comparison of native Dutch and immigrant households in the Netherlands*
}

\author{
Chris van Klaveren Bernard van Praag \\ $\&$ \\ Henriette Maassen van den Brink
}

\begin{abstract}
Although the number of immigrant households in the Netherlands is substantial, the labor supply choices of this group are usually neglected in empirical studies because these households are usually under-sampled. We use a stratified sample of Turkish, Surinamese/Antillean and Dutch households that enables us to discuss how two-earner households allocate their time to different activities. In order to do so, we empirically estimate a collective household labor supply model.

The main findings are that: (1) Leisure and household income are the most important variables in the utility function of the male; (2) Leisure, total household production and total household production interacted with family size are important variables in the utility function of the female. The latter two are especially important for Turkish and Surinamese/Antillean females; (3) The utility of Turkish and Dutch males weighs slightly more than the utility of the partner in the household utility function. For Surinamese/Antillean families we find the opposite; (4) Utility weighting depends on the presence of children and on the hourly wage rates of both partners; (5) The labor supply curve is forward bending for both male and female in terms of their own wage. The labor supply curve is backward bending for both male and female in terms of the partners wage. We find this for all household types; (6) The presence of (more) children reduces the hours of labor supplied by women and increases the number of hours supplied by men.
\end{abstract}

JEL Codes: D12, D13, J22

Keywords: Collective household models; Labor supply; Intra-household ; Time allocation; Immigrant households

${ }^{*}$ The authors are affiliated with SCHOLAR, a research institute on schooling, labor market and economic development; Department of Economics and Econometrics, University of Amsterdam, Roetersstraat 11, 1018 WB Amsterdam, The Netherlands, NWO Priority Program 'Scholar'. Van Praag is also affiliated with $I Z A, D I W$ and CESifo. Contact author: c.p.b.j.vanklaveren@uva.nl. 


\section{Introduction}

By now it is generally recognized that the behavior of partners, living in the same household, is interdependent. This holds for individual consumption and for labor supply. There are several ways to describe the behavior of individuals in multi-person households in the economic literature. The traditional approach is the unitary approach, where the household is considered as one individual. Bourguignon, Chiappori \& Lechene (1994), Fortin \& Lacroix (1997) and Browning \& Chiappori (1998) among others have shown that this assumption is unten-

able. Two other approaches are the Nash-bargaining approach (see Manser \& Brown (1980), McElroy \& Horney (1981) and Lundberg \& Pollak (1993, 1994)) and the collective household approach (see Chiappori $(1988,1997)$ and Apps \& Rees $(1988,1997))$. In the Nash bargaining approach partners bargain with each other in order to profit from the gains that can be obtained by the fact that they are married.

In the collective approach, initiated by Chiappori(1988, 1997) and Apps \& Rees $(1988,1997)$ the two partners look for a Pareto equilibrium. They maximize their own utility taking into account the utility of the partner. This model is often described as maximizing a household collective utility function, that is a $\pi$-weighted sum of the two individual utility functions. The weight $\pi$ that lies between 0 and 1 stands for the relative power of the male and $(1-\pi)$ for the relative power of the female in this collective decision process. The partners behave as if the household $n$ optimizes a collective utility function of the following type: $U_{h, n}=\pi_{n} \cdot U_{m, n}+\left(1-\pi_{n}\right) \cdot U_{f, n}$. In the model it is merely assumed that the outcome of the household decision process should be a Pareto-efficient outcome.

Making use of the theoretical framework of the collective model, the utility function of male and female have been empirically estimated by Van Klaveren, Van Praag \& Maassen van den Brink $(K P M)(2005)$ for a data set of British twobreadwinner households; moreover, the weight $\pi_{n}$ was estimated for individual households, assuming that the within-household power distribution is a function 
of household characteristics. In particular, the effects of wage differences and the presence of children on the relative power distribution have been estimated. In this paper we use the $K P M$-approach to estimate a collective household model of time allocation where we distinguish between immigrant households and Dutch households.

Like all Western countries, the Netherlands has a sizeable minority of immigrants. Nowadays almost 10 percent of the Dutch population consists of non-Western (first- or second- generation) immigrants and this number is expected to increase to over 20 percent in the year 2050 (CBS (2003a)). The four largest immigrant groups are from Turkey, Morocco, Surinam and the Dutch Antilles. During the 1950's the Dutch decolonization process attracted immigrants from Indonesia. In the 1960's inhabitants of Surinam and the Antilles received the Dutch nationality, which gave them the right to work and live in the Netherlands (Cornelisse-Vermaat (2005)). In the 1960's and 1970's, when the Dutch economy flourished, Surinamese, Antillean and Turkish workers came to the Netherlands to find a (low income) job. In general these immigrants were males with the initial intention to stay in the Netherlands only temporarily. Most of them stayed permanently. The immigrants that we consider in this study are of Surinamese/Antillean and of Turkish descent. they are compared to a group of native Dutch.

The first group stems from the former Dutch colonies of Surinam and the Dutch Antilles. Their mother tongue is frequently Dutch and they basically got Dutch education. Some of them are in the Netherlands for thirty years or more, others immigrated rather recently in the last decade. The Turkish minority is one of the largest minorities in the Netherlands. Most of them came from relatively backward regions in Turkey; they are Muslim and frequently they only speak Turkish within the family. Many Dutch Turks have double nationality but a large part of them choose marriage partners from their homeland, which immigrate under the law of Family Reunion. Their education level is relatively low compared to the Dutch. The main integration problem for both groups that are addressed by the Central bureau of Statistics $(C B S)$ and the Social Cultural 
Planning Bureau $(S C P)$ are the high number of unemployed immigrants compared to the native Dutch (see $C B S$ (2003b), SCP (2002)), the lower education levels of immigrants (see $S C P$ (2003)) and according to the Scientific Council of Government policy $(W R R)$ the lack of cohesion between immigrant groups and the native Dutch (WRR (2001)).

In spite of the fact that immigrant households are a substantial and growing group within the total Dutch household population, they are usually undersampled or neglected in general surveys. As far as they participate in a survey, members of those sub-populations are usually lumped together with the main population of Dutch descent. Especially research on household labor supply decisions in the Netherlands tends to neglect the household labor supply decision process of these immigrants (an exception is Cornelisse-Vermaat (2005)).

The novelty of this paper is that we estimate a collective household time allocation model for two-earner households where we distinguish between immigrant households and Dutch households. The relevance of this paper is twofold. First, estimating a collective household labor supply model for three different samples of respectively Dutch, Surinamese/Antillean and Turkish descent, we may discover sociologically interesting differences between these three populations with presumably rather different values and cultures. Second, it provides a test of the applicability of the $K P M$-estimation method on other samples. The answer will be positive.

In section 2 we specify the collective household model we plan to estimate. In section 3 we describe the data that are used. In section 4 the estimation method is described. In section 5 the estimation results are presented. In section 6 we discuss the wage and child effects and finally, section 7 we conclude.

\section{The Model}

The theoretical model in this section is based on a model developed earlier in KPM (2005).

The utility function of either partner is assumed to be a log-additive utility 
function. The arguments of this utility function are leisure time (le), time spent in the household $(w h)$, job hours $(j h)$, household income $(Y)$, the joint household care level $(H)$ and family size $(f s)$. Family size is defined as the number of children living in the household. The male's utility function is

$$
\begin{aligned}
U_{m} & =\alpha_{m, 1} \ln \left(l e_{m}\right)+\alpha_{m, 2} \ln \left(w h_{m}\right)+\alpha_{m, 3} \ln (H) \\
& +\alpha_{m, 4} \ln (f s+1) \cdot \ln (H)+\alpha_{m, 5} \ln (Y)+\alpha_{m, 6} \ln \left(j h_{m}\right)
\end{aligned}
$$

where

$Y=w_{m} \cdot j h_{m}+w_{f} \cdot j h_{f}+y_{u}$

$H=w h_{m}+\zeta \cdot w h_{f}$

$j h_{m}=T-l e_{m}-w h_{m}$

$j h_{f}=T-l e_{f}-w h_{f}$

Notice that in the definition of the joint household care level $H$, one hour of household time of the male is assumed to be $\zeta$ times as effective as one hour of household time of the female. Here the value $\zeta$ may be greater or smaller than one. Notice furthermore that the second and third/fourth term in the utility function make it possible to distinguish between the utility or disutility that is derived from individual household chores and the utility that is derived from the joint household production as a public good. The interaction coefficient $\alpha_{m, 4}$ gives room for an effect of the presence of children on the utility value of $H$, as it may be that the effect of the number of household work hours on utility varies with the household size. The total weekly time endowment of 168 hours is denoted as $T$. The net wage rates of male and female are denoted by $w_{m}$ and $w_{f}$, respectively. The $y_{u}$-term stands for the net weekly non-labor household income. Unfortunately, we are unable to identify which part of $y_{u}$ stems from the male and which part stems from the female.

According to the collective approach we may view household $n$ 's behavior as the outcome of maximizing a household utility function of the following type: 


$$
U_{n, h}=\pi_{n} U_{n, m}+\left(1-\pi_{n}\right) U_{n, f}
$$

The household utility function can be seen as a weighted sum of the two individual utility functions. Since the weight distribution may be different for each household it follows that the power coefficient $\pi_{n}$ may vary over households. When we would describe the optimization problem in the Lagrangean form it follows that the household utility function is concave with explicit linear constraints and so there exists one unique optimum under these linear constraints. Without loss of generality we may assume $0 \leq \pi \leq 1$.

Let us assume that the male allocates his time such that the collective utility function is maximized. The corresponding first-order-conditions $(F O C)$ for the male's leisure time and hours of household work are then after re-ordering

$$
\begin{gathered}
\frac{\partial U_{h}}{\partial l e_{m}}=\frac{\partial U_{f}}{\partial l e_{m}}+\pi\left(\frac{\partial U_{m}}{\partial l e_{m}}-\frac{\partial U_{f}}{\partial l e_{m}}\right)=0 \\
\frac{\partial U_{h}}{\partial w h_{m}}=\frac{\partial U_{f}}{\partial w h_{m}}+\pi\left(\frac{\partial U_{m}}{\partial w h_{m}}-\frac{\partial U_{f}}{\partial w h_{m}}\right)=0
\end{gathered}
$$

For the female we find two similar equations. We notice that each of the FOC's in (3) and (4) consists of three terms. The first and the third term refer to the 'female' part of the collective utility function. This is due to the fact that household income and the total household production figure in the utility functions of both partners. The number of hours $w h_{f}$ that the female works in the household affects the level of well-being of the male. The same holds for the working hours $j h_{f}$ of the female, because the net wage of the female is part of the household income.

In KPM (2005) it was shown that equations (3) and (4) may be rewritten as linear expressions in the utility parameters $\left(\alpha_{m}, \alpha_{f}\right)=\alpha$ of the male and female and corresponding coefficients that are non-linear expressions in $l e_{m}$ 
$l e_{f}, w h_{m}, w h_{f}, w_{m}, w_{f}$. For example, if we obtain the derivative $\frac{\partial U_{m}}{\partial l e_{m}}$ we get:

$$
\frac{\partial U_{m}}{\partial e_{m}}=\frac{\alpha_{m, 1}}{l e_{m}}-\frac{\alpha_{m, 5} \cdot w_{m}}{w_{m}\left(j h_{m}\right)+w_{f}\left(j h_{m}\right)+y_{u}}-\frac{\alpha_{m, 6}}{j h_{m}}
$$

The first coefficient may then be denoted as $x_{1, m, 1}=\frac{1}{l e_{m}}$. As $\alpha_{m, 2}$ does not appear in the first $F O C$ we have $x_{1, m, 2}=0$. We shortly denote the coefficient vector of the first FOC, referring to the male's utility function, by a vector function $x_{1, m}\left(l e_{m}, l e_{f}, w h_{m}, w h_{f}, w_{m}, w_{f}\right)$. More concisely, we may write the first FOC as

$$
x_{1 f}^{\prime} \alpha_{f}+\pi\left(x_{1 m}^{\prime} \alpha_{m}-x_{1 f}^{\prime} \alpha_{f}\right)=0
$$

where $\alpha$ stands for a 12 -vector of utility parameters and $x_{1}^{\prime}=\left(x_{1 m}^{\prime}, x_{1 f}^{\prime}\right)$ for a twelve- dimensional vector function of $l e_{m}, l e_{f}, w h_{m}, w h_{f}, w_{m}, w_{f}$. The index 1 refers to the $x$ - vector in the first FOC. In a similar way the other FOC's with respect to $w h_{m}, l e_{f}$ and $w h_{f}$ can be determined. Hence, this yields a system of four equations

$$
\left[\begin{array}{l}
\pi x_{1 m}^{\prime}+(1-\pi)\left(x_{1 f}^{\prime}\right) \\
\pi x_{2 m}^{\prime}+(1-\pi)\left(x_{2 f}^{\prime}\right) \\
\pi x_{3 m}^{\prime}+(1-\pi)\left(x_{3 f}^{\prime}\right) \\
\pi x_{4 m}^{\prime}+(1-\pi)\left(x_{4 f}^{\prime}\right)
\end{array}\right] \alpha=\left[\pi X_{m}^{\prime}+(1-\pi) X_{f}^{\prime}\right] \alpha=0
$$

where $X_{m}^{\prime}$ and $X_{f}^{\prime}$ are $(4 \times 12)$-matrices. For household $n$ we define the matrix $X_{n, h}^{\prime}$ by

$$
\left[\pi_{n} X_{n, m}^{\prime}+\left(1-\pi_{n}\right) X_{n, f}^{\prime}\right]=X_{n, h}^{\prime}
$$

In the remainder of this paper we use the short-hand notation $z=$ $\left(l e_{m}, w h_{m}, l e_{f}, w h_{f}\right)$.

The left-hand-side of system (6) is the gradient of the household utility function $U_{h}(z)$. We shall write it sometimes as the 4 -vector $U_{h}^{\prime}(z)$ or alternatively 
as $U_{z}$. The above system describes the equilibrium where the gradient vector equals the zero vector. The $(4 \times 4)$-matrix of second-order derivatives of $U_{h}(z)$ is denoted by $U_{h}^{\prime \prime}$ or $U_{z z}$.

The power coefficient $\pi$ is a parameter that varies over households. We assume that the weight distribution between male and female depends on some personal characteristics, in short a vector $\left(v_{m}, v_{f}\right)$ of power characteristics. The following power characteristics are selected: the hourly wages of the two partners, the number of children divided over several age categories and the ages of the two partners. We specify:

or

$$
\pi_{n}(v)=N\left(\beta_{1} \ln \left(w_{n, m}\right)-\beta_{2} \ln \left(w_{n, f}\right)+\sum_{j=3}^{J} \beta_{j} \cdot T_{j, n}\right)
$$

where $N(\cdot)$ stands for the standard normal distribution function. Here we choose this functional specification because it is flexible and $\pi$ is automatically constrained in $[0,1]$, while the argument can take any value on the real axis. In other words, we use the normal distribution function without any probabilistic connotation. For reasons of simplicity we have listed the wage characteristics separately in equation (8) and hence the term $\sum_{j=3}^{J} \beta_{j} \cdot T_{j, n}$ contains the other characteristics that may influence the power distribution. If $\beta_{3}=\ldots=\beta_{J}=0$, and if $\beta_{1}=\beta_{2}$ and $w_{m}=w_{f}$, we find $\pi(v)=\frac{1}{2}$. This is the case of an equal power distribution between husband and spouse. The weight $\pi(v)$ increases in the male's wage and decreases in the female's wage. If $\beta_{1} \neq \beta_{2}$, the weight is asymmetric, that is, even if $w_{m}=w_{f}$, we may have $\pi(v) \neq \frac{1}{2}$.

Browning, Chiappori \& Lechene (2004) call a model that is making use of a power function a collective model. They conclude that when the power function is not assumed to depend on prices, or in our model wages, then the model is equivalent to the standard unitary model. The dependency of the power function on wage rates is a necessary condition. 


\section{Data}

The data set was collected between September and November 2001 by DESAN, a Dutch organization for market research. The aim was to create a balanced sample with as many Dutch households as Turkish and Surinamese/Antillean households. The Dutch sub-sample is randomly drawn from the total pool of phone numbers of the Royal Dutch Mail $(K P N)$. The immigrant sub-sample is drawn from a register owned by DESAN ${ }^{1}$. We include second-generation households but not mixed marriages.

Table 1 shows the frequency table of the number of two breadwinner households differentiated according to ethnical background.

\section{-Insert Table 1 about here-}

According to the Central Bureau of Statistics $(C B S)$, an individual is considered to be an immigrant, if at least one of the parents is born abroad $(C B S$ (2000)). There is no information with respect to the parental ethnicity of the respondent's partner. Hence, we define the ethnicity of a certain household by characterizing the ethnicity of the respondent following the definition of the $C B S$ and the ethnicity of the partner by using the direct question about the ethnicity of the partner. If respondent and partner have the same ethnicity, the household is classified as Dutch, Surinamese/Antillean or Turkish.

In order to estimate the proposed model we need to have information regarding time spent on paid labor, leisure and household tasks. Although the data provide all this information for the respondent, for the respondent's partner only paid labor hours are known but not the time spent on household tasks. Hence, the time spent on household tasks by the partner has to be imputed on the basis of relevant characteristics. We notice that in the data the choice of the responding individual was random. That is, the respondent is not necessarily the male adult in the household or the one who has the highest labor income.

\footnotetext{
${ }^{1}$ Households from the second generation cannot be labelled as immigrants. However for reasons of simplicity we will refer to Turkish, Surinamese/Antillean households as immigrant households, although strictly speaking this is not the right definition of an immigrant household.
} 
Let us first define the number of working hours, spent on household tasks by the respondent as $w h_{r}$ and that of the partner as $w h_{p}$. Notice that the total time endowment per week is 168 hours and so we want the imputed value of $w h_{p}$ to be in the interval $[0,168]$. Therefore, we define the auxiliary variable $\gamma$ by:

$$
\gamma_{n, r}=\log \left(\frac{w h_{n, r}}{168-w h_{n, r}}\right)
$$

Using the information of respondents $\gamma_{n, r}$, we estimate the following equation by means of Ordinary Least Squares $(O L S)$ :

$$
\gamma_{n, r}=\delta_{0}+\delta_{1} \cdot s_{n, 1}^{h}+\ldots+\delta_{k} \cdot s_{n, k}^{h}+\delta_{k+1} \cdot s_{n, k}^{r}+\ldots+\delta_{K} \cdot s_{n, K}^{r}+\epsilon
$$

Where $s_{n}^{h}$ are household characteristics and $s_{n}^{r}$ are individual characteristics of the respondents for the $N$ available households. The estimation results are shown in Table 2.

\section{-Insert Table 2 about here-}

Notice that $w h_{r}=\frac{168}{1+e^{-\gamma_{n, r}}}$. Hence if $\gamma=0$ then $w h_{r}=84$, if $\gamma \rightarrow \infty$ then $w h_{r} \rightarrow 168$ and if $\gamma \rightarrow-\infty$ then $w h_{r} \rightarrow 0$. A positive effect of the explanatory variables on $\gamma$ can thus be interpreted as a positive effect on household time.

As is expected, males spend less time on household tasks compared to females. The presence of children increases the number of hours spent on household work. The estimation results suggest that ethnicity does not influence the amount of time spent in the household significantly.

By estimating equation (10) and obtaining $\hat{\delta}_{1}, \ldots, \hat{\delta}_{K}$ we can impute the missing values $w h_{n, p}$ for partner $p$ by calculating $\hat{\gamma}_{n, p}$ :

$$
\widehat{\gamma}_{n, p}=\hat{\delta}_{0}+\hat{\delta}_{1} \cdot s_{n, 1}^{h}+\ldots+\hat{\delta}_{j} \cdot s_{n, k}^{h}+\hat{\delta}_{k+1} \cdot s_{n, k}^{p}+\ldots+\hat{\delta}_{n} \cdot s_{n, K}^{p}
$$

Notice that in equation (11) the respondent's characteristics are replaced by the characteristics of the partner whose household work hours $w h_{p}$ are unknown. 
Using $\hat{\gamma}_{n, p}$ and equation (9) we can obtain values for $\hat{w} h_{n, p}$ in $[0,168]$ from $\hat{\gamma}_{n, p}$ by inverting (9) as

$$
w h_{n, p}=\frac{168}{1+e^{-\hat{\gamma}_{n, p}}}
$$

In table 3 we present the partly imputed and partly observed time use statistics for the 3 distinguished household types.

\section{-Insert Table 3 about here-}

The descriptive statistics of Table 3 reveal that males work more hours in paid labor than females, while the opposite is true for the amount of hours spent on household work. Furthermore, males tend to be older than their partners and slightly higher educated.

Dutch (fe)males have a higher hourly wage than immigrant (fe)males. This is in line with the data of Netherlands Statistics $(C B S)$.

The Surinamese males tend to be equally well educated as Dutch males; Surinamese females are less educated than Dutch females and they have a lower hourly wage. But in contrast they work more hours on the labor market than Dutch females. This results in a household income for Surinamese/Antillean households, that is approximately equal to that of Dutch households. It should be noticed that highly educated Surinamese/Antillean males happen to be overrepresented $\mathrm{n}$ this sample and this might have affected the averages in table 3 . The household income of Turkish households is smaller than Dutch households, as is expected.

When we compare the family size of the various ethnical groups we notice that the immigrant households have more children than Dutch households.

\section{The Estimation Method.}

Given the proposed theoretical model it is possible to determine the FOC's with respect to $l e_{m} w h_{m}, l e_{f}$ and $w h_{f}$. This yields the following system (see equations (6) and (8)) of four equations for each household $n$ : 


$$
\left[\pi_{n}\left(\beta ; v_{n}\right) \cdot X_{n, m}^{\prime}+\left(1-\pi_{n}\left(\beta ; v_{n}\right)\right) \cdot X_{n, f}^{\prime}\right]\left[\begin{array}{c}
\alpha_{m} \\
\alpha_{f}
\end{array}\right]=X_{n}^{\prime}\left(\pi_{n}\right) \alpha=0
$$

Where $X_{n}$ and $\pi_{n}$ is a short hand notation for the first matrix in (13). Notice that $X_{n}$ is a linear function in $\pi_{n}$. We assume that $\pi_{n}=\pi_{n}\left(\beta ; v_{n}\right)$ is constant for each household but that it is varying over households with a vector $v_{n}$. The parameter vector $\beta$ has to be estimated. Solving this system for $l e_{m} w h_{m}, l e_{f}$ and $w h_{f}$ for each $n$ would give the optimal solution vector $z^{\star}=$ $\left(l e_{m}^{\star}, w h_{m}^{\star}, l e_{f}^{\star}, w h_{f}^{\star}\right)$. Then we might compare $z_{n}^{\star}$ with the observed $z_{n}$ and find the optimal parameter estimates that would minimize the difference between $z_{n}^{\star}$ and $z_{n}$. However, this solution vector $z^{\star}$ is highly non-linear in the $\alpha$ and $\beta$ parameters. Consequently, it is difficult to estimate the unknown parameters by a direct method. We propose a more convenient indirect estimation method in order to estimate the unknown parameter vector $(\alpha, \beta)$. It is inspired by the fact that (13) is linear in the parameter vector $\alpha$.

First, we assume that $\beta$ is known and so $\pi_{n}$ is known for each household. Since the matrix equality in (13) does not hold exactly, we add a stochastic component and assume

$$
X_{n}^{\prime} \alpha=\varepsilon_{n}
$$

where $\varepsilon$ is an error vector for which holds that $\varepsilon \sim N\left(0, \Sigma_{\varepsilon}\right)$. We assume that the error components are not correlated between households, i.e., $E\left(\varepsilon_{n}, \varepsilon_{n^{\prime}}\right)=0$ if $n \neq n^{\prime}$.

The system in equation (14) can be estimated by minimizing the sum of squared residuals $\sum_{1}^{N} \varepsilon_{n}^{\prime} \Sigma_{\varepsilon}^{-1} \varepsilon_{n}=\sum_{1}^{N} \alpha^{\prime} X_{n} \Sigma_{\varepsilon}^{-1} X_{n}^{\prime} \alpha$ with respect to $\alpha$. The 'trivial' solution is excluded by two identifying conditions $\sum \alpha_{m}=1$ and $\sum \alpha_{f}=$ 1.

However, the estimation of the full collective model is more complex, since the $\beta$ coefficients are unknown as well. Therefore, we solve the estimation 
problem by an iterative procedure.

In the first step we set $\beta_{1}^{(1)}=\ldots=\beta_{J}^{(1)}=1$ yielding the first round power coefficients $\pi_{n}^{(1)}$. The superscript indicates the iteration round. Notice that these coefficients are not constant, as households have different characteristics. Then we estimate the $\alpha$ coefficients, given $\pi_{n}^{(1)}$.

Consider the system of four equations

$$
y_{n}=X_{n}^{\prime} \alpha+\varepsilon_{n}
$$

where $y_{n}$ is a nuisance vector. This system can be estimated by the method of Seemingly Unrelated Least Squares $(S U R)$. If we set $y_{n}=0$ for all $n$, estimation of this system under the constraints $\sum \alpha_{m}=1$ and $\sum \alpha_{f}=1$ is equivalent to minimizing $\sum_{1}^{N} \alpha^{\prime} X_{n} \Sigma_{\varepsilon}^{-1} X_{n}^{\prime} \alpha$ with respect to $\alpha$ under those constraints.

The estimated $\alpha$-coefficients are denoted by $\alpha^{(1)}$. On the basis of these estimate of $\alpha^{(1)}$, we estimate $\beta_{1, \ldots, J}$ denoted by $\beta^{(2)}$ that will be used in the second iteration round.

In the second iteration round we determine $\pi_{n}^{(2)}$ by using $\beta^{(2)}$. Then $\alpha$ is re-estimated and with these $\alpha^{(2)}$ coefficients we estimate $\beta^{(3)}$. These $\beta$ 's are then used in the third iteration round. We continue this iterative process until convergence is reached.

\section{Estimation Results}

Given the observed quantities of time that are allocated to certain activities and assuming that individuals maximize their utility following the collective household model we can estimate the preference parameters $\left(\alpha_{m}, \alpha_{f}\right)$ and the power parameters $\beta$ for the Dutch, Surinamese/Antillean and Turkish households. The estimation results $\left(\alpha_{m}, \alpha_{f}\right)$ are shown in Table 4 and those for $\beta$ in Table 5 .

-Insert Table 4 about here- 
Following the definition of household tasks it is not assumed that household hours of male and female are perfect substitutes $(\zeta=1)$. In order to asses $\zeta$, we let $\zeta$ vary with a width of 0.025 and choose the $\zeta$ estimate that yields the highest $\log$ likelihood of the linear parameters. The rate of substitution of time spent in the household is 0.975 for Dutch, 1.35 for Surinamese/Antillean households and 0.8 for Turkish households. It seems that the marginal household hour of the Surinamese/Antillean female is more valuable than that of their partner. The marginal household hour of the Dutch male is about equal to that of the Dutch female and the marginal household hour of the Turkish male is more valuable than that of the Turkish female.

However, we notice that $\zeta$ might reflect the ratio of productivity but it may also be the case that $\zeta$ is influenced by cultural backgrounds where different norms and values apply. It is well-known that the roles of male co-workers in the household is very differently interpreted in the three ethnic communities considered. Hence, we do not make a productivity statement based on the value of the $\zeta$ parameter. However, the model is more flexible by allowing for the fact that the rate of substitution may be different from 1 .

When concentrating on the preference parameters $\alpha$ we notice that in $K P M$ (2005) we estimated the same collective household model for British households using the British Household Panel Survey. The estimated preference parameters of that study appear to be very similar to the estimated preference parameters we obtain for Dutch households. For Dutch males the most important variables in their utility function are leisure and household income. For Dutch females leisure time seems to be the most important variable and household income less so, which is a general finding. On average the labor participation of Dutch females is the same as in surrounding countries. However, the amount of hours that Dutch females work on the labor market is on average lower than that in other European countries. Although Dutch females do not derive utility from individual household chores, they do find joint household production important. So household tasks have to be done, but preferably not by themselves but by the partner. The importance of joint household production increases when the 
family size is larger.

For Surinamese/Antillean males it holds that leisure and household income are the most important variables in the utility function. For Surinamese/Antillean females we find that leisure, joint household production and joint household production interacted with family size are important. We notice that the estimation results of Dutch males and Surinamese/Antillean males are very similar, which may be due to the fact that the background characteristics of these males are rather similar as can be seen from the descriptive statistics in Table 3.

Surinamese/Antillean and Dutch females appear to have different preferences. While joint household production and joint household production interacted with family size significantly enter the utility function of both Dutch and Surinamese/Antillean females, these variables are much more important for the latter group.

Turkish families appear to be different both from Surinamese/Antillean and Dutch households. The most important variable for Turkish males is leisure. Other, but less important variables, are household income and job hours. They derive prestige from their work. Household production and household production interacted with family size, appear negatively in the utility function of Turkish males. For Turkish females on the other hand, joint household production and joint household production interacted with family size is very important, just as leisure is important. While leisure is important, the coefficient of leisure is smaller than the leisure coefficient of Surinamese/Antillean and Dutch females (and males).

An explanation for the preference differences between Turkish males and Turkish females is that these households are in general more traditional: men specialize on the labor market and women specialize in household work.

The average power coefficient $\left(\bar{\pi}_{n}\right)$ can be found in Table 4 . An increase of the average power coefficient means that the utility function of the male is more heavily weighed in the collective utility function. The average power coefficient $\left(\bar{\pi}_{n}\right)$ is slightly higher than 0.5 for Dutch households. For Turkish households we also find that the average of the power distribution is slightly above 0.5 , 
while we find for Surinamese/Antillean households that the value is slightly below 0.5 . Although we have only complete households in our sample, this observation may indicate that the relationship between husband and spouse in Surinamese/Antillean households differs from that in Dutch and Turkish households. In Surinamese/Antillean households the female may be more independent from her partner than in the latter two household types. The distributions of $\bar{\pi}_{n}$ for the three types of households are shown in figure 1.

\section{-Insert Figure 1 about here-}

For Dutch households we find that $\pi$ is approximately normally distributed around the mean. The power distribution for Surinamese/Antillean households in the sample is heavily skewed to the left or in other words the median value $\pi_{n}$ is smaller than the average value of $\pi_{n}$. A t-test shows that the mean of $\pi_{n}$ is significantly smaller than 0.5 . This indicates that the weight of females is frequently higher than the weight assigned to the male's utility function in Surinamese/Antillean households.

For Turkish households we find very different values for $\pi_{n}$ for different households, although most values are above 0.5. A $t$-test indicates that the mean value of $\pi_{n}$ is significantly greater than 0.5 . Hence, the utility of Turkish males weighs slightly more than the utility of Turkish females in the collective household utility function.

In general, Figure 1 shows that there is much variation in the distribution of household power between individual households.

\section{-Insert Table 5 about here-}

The estimation results where the power coefficient is explained by various household characteristics is shown in Table 5. For Dutch households we find that age, the hourly wage rate and the number of children that are aged between 0 and 3 influences the power distribution. When partners are about the same age, the age effect will be small. However, if the age difference increases, the power distribution shifts to the advantage of the oldest partner, mostly the male. The 
power distribution shifts in the advantage of the female when there are children present in the household that are aged between 0 and 3 . The wage rate effects are as expected, the power distribution will shift to the direction of the partner whose hourly wage rate increases.

For Surinamese/Antillean households the variation in the power distribution is entirely driven by the presence of children in the household. The more children aged below sixteen are present in the household, the more the power distribution will shift in the direction of the female. Wages have a non-significant effect.

For Turkish households we find a similar wage rate effect as found for Dutch households, although the effects are not as strong. Furthermore, for Turkish households the presence of children also tends to shift the power distribution towards the female.

\section{$6 \quad$ Wage and Child effects}

Since labor supply and leisure time choices depend on the wage rates of both partners it is interesting to examine how labor supply and leisure consumption depend on wage changes. More formally, it is interesting to examine how a change of the wage vector $\left(w_{m}, w_{f}\right)=w$ with $\Delta w$ influences the solution vector $z(w)=z=\left(l e_{m}^{\star}, w h_{m}^{\star}, l e_{f}^{\star}, w h_{f}^{\star}\right)$.

Consider again the system that we estimated:

$$
\left[\begin{array}{l}
\pi x_{1 m}^{\prime}+(1-\pi)\left(x_{1 f}^{\prime}\right) \\
\pi x_{2 m}^{\prime}+(1-\pi)\left(x_{2 f}^{\prime}\right) \\
\pi x_{3 m}^{\prime}+(1-\pi)\left(x_{3 f}^{\prime}\right) \\
\pi x_{4 m}^{\prime}+(1-\pi)\left(x_{4 f}^{\prime}\right)
\end{array}\right] \alpha=\left[\pi X_{m}^{\prime}+(1-\pi) X_{f}^{\prime}\right] \alpha=0
$$

This $(4 \times 12)$ - matrix $X$ is a function of $w($ through $\pi)$ and differentiating the elements of $X$ also with respect to $w$, gives two extra columns to the matrix

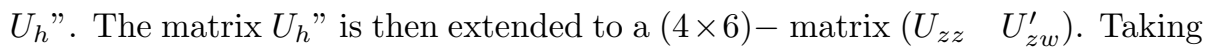
into account that the power distribution depends on the wage rates as well, we 
have:

$$
\begin{aligned}
U_{z z} & =\pi \cdot U_{m, z z}+(1-\pi) \cdot U_{f, z z} \\
U_{z w}^{\prime} & =\pi \cdot U_{m, z w}^{\prime}+(1-\pi) U_{f, z w}^{\prime}+\left[\frac{\partial \pi}{\partial w}\right]\left[U_{m, z}-U_{f, z}\right]^{\prime}
\end{aligned}
$$

Hence, the wage effect matrix is

$$
\frac{\partial z}{\partial w}=-\left(U_{z z}\right)^{-1}\left[\pi U_{m, z w}^{\prime}+(1-\pi) U_{f, z w}^{\prime}+\left[\frac{\partial \pi}{\partial w}\right]\left[U_{m, z}-U_{f, z}\right]^{\prime}\right]
$$

Using equation (18) we can obtain the corresponding elasticities, $\frac{\partial z}{\partial w} \cdot \frac{w}{z}$. Notice that the elasticities are evaluated in the sample gravity point. Table 6 shows the wage elasticities for the three household types.

\section{-Insert Table 6 about here-}

The wage elasticities for Dutch males and females are remarkably symmetric. The individual whose wage increases tends to work more hours on the labor market while the partner, given that the partner's wage remains constant, tends to work less hours on the labor market. Hence, we find a forward bending labor supply curve for both Dutch household members. The female tends to work more labor hours and spends less hours on household activities if her wage increases. As a consequence, the male will work less hours on the labor market and compensates the number of hours that is worked in the household, such that the joint household production in terms of household hours remains the same.

Also for Surinamese and Antillean households we find a forward bending labor supply curve for both male and female. The wage elasticities of Surinamese and Antillean males are very similar to those of Dutch males. As mentioned earlier, the descriptive statistics for Dutch and Surinamese males are very similar and this probably explains the similarities in the wage elasticities. A wage 
increase of the female does have less impact on the time spent on household tasks by male and female than for Dutch households. This might be due to the fact that Surinamese/Antillean females already spend a large amount of hours on household tasks.

Turkish females tend to work more hours on the labor market when their wage rate increases. The effect of a wage rate increase on the labor supply of the Turkish male is much smaller than for the Turkish female, and also smaller than for Dutch and Surinamese/Antillean males. Furthermore, when females tend to work more labor hours as a result of a wage rate increase, this will lead to an increase of the number of hours that Turkish males spend on household tasks.

In general we can conclude that the labor supply curves for both males and females are forward bending in terms of their own wages. The labor supply curves in terms of the partner's wage are backward bending. In labor supply literature it is generally found that the labor supply curve of men is backward bending (see Pencavel (1986)) and that the labor supply curve of the female is forward bending (see Killingsworth \& Heckman (1986)). Comparing our results to results mentioned in Killingsworth \& Heckman (1986) and Pencavel (1986) we find similar results for women but we find the opposite for men, namely, an increase of the hourly wage rate will lead to more hours of labor supply. In our study we obtain cross elasticities and this might explain the change in result that we find for men.

The child effects can be obtained in a similar way as the wage effects are obtained. We expect to find that having young children will have a negative effect on labor supply, most likely for females. The effect of having children can be obtained by using equation (18)

$\frac{\partial z}{\partial \ln \left(C_{l}^{u}\right)}=-\left(U_{z z}\right)^{-1}\left[\pi U_{m, z f s}^{\prime}+(1-\pi) U_{f, z f s}^{\prime}+\frac{\partial \pi}{\partial \ln \left(C_{l}^{u}\right)} \cdot\left[U_{m, z}-U_{f, z}\right]^{\prime}\right]$

Where $C_{l}^{u}$ is the number of children within a certain age interval. The 
$l$-subscript indicates the lower age bound and the $u$-superscript indicates the upper age bound. The corresponding elasticities are then $\frac{\partial z}{\partial \ln \left(C_{l}^{u}\right)} \cdot \frac{\partial \ln \left(C_{l}^{u}\right)}{z}$ and again the elasticities are evaluated in the sample gravity point. The results are shown in Table 7

\section{-Insert Table 7 about here-}

In general we find that the presence of (more) children in the household has a negative effect on the labor supply of females for all household types. This effect is the largest for Turkish females.

Dutch and Turkish males supply more labor hours when the number of children increases while Surinamese/Antillean males supply less hours of labor when there are young children present in the household and supply more hours of labor when there are older children in the household.

For Turkish and Dutch households we find that although males increase the hours spent on household activities when there are (more) children between 0 and 3, they do not increase the number of hours on household activities when the children are older than 3 years old. The females tend to spend more hours on household activities when there are more children present in the household. It seems that in Dutch and Turkish families the male specializes on the labor market, while the female specializes in household tasks.

For Surinamese/Antillean families it seems that men and women are very similar in changing their time allocation when there are more children present who are 11 years old or younger. Both male and female will reduce their labor supply hours and increase the hours spent on household activities. However, when there are more children present above 12, then the female tends to spend more time on household activities while the male reduces his time spent on household activities. 


\section{Conclusion}

In this paper we analyzed the time allocation within two-breadwinner households , distinguishing between Dutch, Turkish and Surinamese/Antillean households. We find for all households that the most important variables are leisure and household income. Although total household production and total household production interacted with family size are important for all household types it is much more important for Turkish and Surinamese/Antillean females.

Power $\pi_{n}$ in Dutch households is approximately normally distributed around a mean of 0.549 in favor of the male. For Surinamese/Antillean households $\left(\pi_{n}=0.473\right)$ and Turkish households $\left(\pi_{n}=0.523\right)$ we find that the distribution is heavily skewed to the right with fat tails to both sides.

While the power weight depends on the hourly wage rates for Dutch and Turkish households, this is not the case for Surinamese/Antillean households. An increase in the individual's wage rate in Dutch or Turkish households will shift the power distribution in favor of this individual. Having children affects the power distribution as well. While we find that having children from 0 to 3 years shifts the power distribution in the advantage of the female for Dutch households, we find that this children effect is larger for Surinamese/Antillean and Turkish households. Furthermore, for Surinamese/Antillean and Turkish households we also find the same effect for the presence of older children in the household.

Since labor supply and leisure time choices depend on the wage rates of both partners we examined how these choices depend on wage changes. In general we find that the labor supply curve is forward bending for both male and female in terms of their own wage. The labor supply curve is backward bending for both male and female in terms of their partner's wage. In other words, males and females will increase the number of hours supplied on the labor market, when their own wage rate increases and will decrease their labor supply when their partner's wage increases. The wage elasticities for Dutch males and females are remarkably symmetric. The wage elasticities for Surinamese/Antillean and 
Dutch males are very similar, probably because their background characteristics are very similar. While studies generally find (see Killingsworth \& Heckman (1986) and Pencavel (1986)) a backward bending labor supply curve for men, we find a forward bending labor supply curve. It is possible that we find different results since we allow for the fact that the choice of labor hours of male and female are interdependent.

The presence of (more) young children in the household reduces the hours of labor supplied by the female and increases the hours of labor supplied by the male. For Turkish and Dutch households this result is found for children of all age categories ; for Surinamese/Antillean households this result is only found for the presence of (more) children of twelve years and older. So the labor market behavior between Turkish and Dutch households appear to be very similar, while Surinamese/Antillean households show a different labor market behavior when there are children present in the households up to 12 years old.

In general we may conclude that a wage rate increase of the female will result in more labor hours supplied, as is the point of departure for current Dutch government policies. However, an important note should be made here. If females increase the number of labor hours due to an increase of their wage rate, at the same time males are likely to decrease their amount of labor hours. For Dutch males and females we even find that the relative increase of female labor hours due to a wage increase of the female is approximately equal to the relative decrease in labor supply by males. As males work more per week, this would induce even a reduction in the aggregate labor supply of the household.Therefore, government tax policy should take these cross-effects into account, when they estimate the prospective tax benefits of female labor incentives.

If child care is subsidized, these cross-elasticities should be taken into consideration as well . Nowadays, it is still the case that women are the primary care givers for children in the household. When child care policies aim at increasing female labor participation then the child care subsidy can be seen as an indirect increase of the female wage rate. However, we found that it is not clear what the labor supply effects become. When females decide to work (more hours) 
because of child care subsidies, then the male might decide to supply less hours of labor and consequently this results in lower participation rates of men and possibly a decrease in the use of day care.

The question how increasing child care subsidies might affect the cross elasticities of wages within the household and consequently labor market participation and the demand for child care is an interesting topic for further research. 


\section{References}

Apps, P. \& R. Rees (1988), 'Taxation and the household', Journal of Public Economics 35, 355-369.

Apps, P. \& R. Rees (1997), 'Collective supply and household production', Journal of Political Economy 105(1), 178-190.

Browning, M., F, Bourguignon, P. A. Chiappori \& V. Lechene (1994), 'Children and household economic behavior', The Journal of Political Economy pp. $1067-1096$.

Browning, M. \& P. A. Chiappori (1998), 'Efficient intra-household allocations: A general characterization and empirical tests', Econometrica pp. 12411278 .

Browning, M., P.A. Chiappori \& V. Lechene (2004), 'Collective and unitary models: a clarification', Working paper .

Centraal Bureau voor de Statistiek (2000), 'Standaarddefinitie allochtonen [standard definition of immigrants]'.

Centraal Bureau voor de Statistiek (2003a), 'Allochtonen in nederland 2003 [immigrants in the netherlands 2003]'.

Centraal Bureau voor de Statistiek (2003b), 'Statistisch jaarboek [statistic annual]'.

Chiappori, P. A. (1988), 'Rational household labor supply', Econometrica 56(1), 63-90.

Chiappori, P. A. (1997), 'Introducing household production in collective models of labor supply', The Journal of Political Economy 105(1), 191-209.

Cornelisse-Vermaat, J. R. (2005), Household production, health and hapiness. A comparison of the native Dutch and non-western immigrants in the Netherlands, $\mathrm{PhD}$ thesis, University of Wageningen. 
Dagevos, J. (2001), 'Perspectief of integratie. over de sociaal-culturele en structurele integratie van etnische minderheden in nederland [perspective on integration. on socio-cultural and structural integration of ethnic minorities in the netherlands]'.

Dagevos, J., M. Gijsbert \& C. van Praag (2003), 'Rapportage minderheden 2003. onderwijs, arbeid en sociaal culturele integratie [report on ethnic minorities. education, market labor and socio-cultural integration]'.

Fortin, B. \& G. Lacroix (1997), 'A test of the unitary and collective models of household labor supply', The Journal of Political Economy 107(443), 933956.

Killingsworth, M.R. \& J.J. Heckman (1986), Female Labor Supply: A Survey, Handbook of Labor Economics, Vol.1 (Amsterdam: North Holland), pp. 103-204.

Lundberg, S. \& R. Pollak (1993), 'Separate spheres bargaining and the marriage market', The Journal of Political Economy 101(6), 988-1010.

Lundberg, S. \& R. Pollak (1994), 'Noncooperative bargaining models of marriage', The American Economic Review 84(2), 132-137.

Manser, M. \& M. Brown (1980), 'Marriage and household decision-making: bargaining analysis', International Economic Review 21(1), 31-44.

McElroy, M. \& M. Horney (1981), 'Nash-bargained household decisions: toward a generalization of the theory of demand', International Economic Review 22(2), 333-349.

Pencavel, J. (1986), Labor Supply of Men : A Survey, Handbook of Labor Economics, Vol.1 (Amsterdam: North Holland), pp. 3-102.

Portegijs, W., A. Boelen \& S. Keuzekamp (2002), 'Emancipatie monitor 2002 [emancipation monitor 2002]'. 
van Klaveren, C., B.M.S. van Praag \& H. Maassen van den Brink (2005), Empirical estimation results of a collective time allocation model. Tinbergen Discussion Paper. 
Table 1: Frequency Table Number of Households by Ethnicity

\begin{tabular}{lrr} 
Ethnicity & Frequency & Percentage \\
\hline & & \\
Dutch & 153 & 42.86 \\
Surinamese/Antilleans & 113 & 31.65 \\
Turkish & 91 & 25.49 \\
& & \\
\cline { 2 - 3 } Total & 357 & 100 \\
\hline \hline
\end{tabular}

Table 2: Estimation results when $\gamma_{k, r}$ is regressed on household and the respondents characteristics

\begin{tabular}{lcr}
\hline Characteristic & Estimate & t-value \\
& & \\
\hline \hline & & \\
Gender dummy & $-0.504^{* * *}$ & -4.90 \\
Hourly wage rate & 0.003 & 0.40 \\
Age & 0.004 & 0.55 \\
Highest education level & -0.030 & -1.11 \\
Log(\#-children 0/3+1) & $1.126^{* * *}$ & 7.31 \\
Log(\#-children 4/11+1) & $0.583^{* * *}$ & 5.03 \\
Log(\#-children 12/15+1) & $0.573^{* * *}$ & 3.86 \\
Log(\#-children 16/25+1) & $0.393^{* *}$ & 2.54 \\
Resp. is Surinamese/Antillean & -0.026 & -0.22 \\
Resp. is Turkish & 0.166 & 1.25 \\
Computer at home & $0.134^{*}$ & 1.82 \\
constant & $-3.251^{* * *}$ & -9.45 \\
& & \\
N & 357 & \\
Adjusted $R^{2}$ & 0.274 & \\
\hline \hline
\end{tabular}


Table 3: Descriptive Statistics

\begin{tabular}{lrrr}
\hline \hline & & & \\
& Dutch & Sur./Ant. & Turkish \\
\cline { 2 - 4 } Male & & & \\
Paid working hours & 39.97 & 37.58 & 39.37 \\
Household hours & 8.24 & 11.33 & 14.74 \\
Leisure & 119.79 & 119.10 & 113.89 \\
Education level & 5.45 & 5.33 & 4.55 \\
Age level & 39.35 & 41.41 & 36.04 \\
Hourly wage rate & 10.00 & 9.65 & 8.19 \\
& & & \\
Female & & & \\
& & & \\
Paid working hours & 25.84 & 29.27 & 26.56 \\
Household hours & 16.69 & 17.89 & 23.59 \\
Leisure & 125.48 & 120.84 & 117.85 \\
Education level & 5.22 & 4.81 & 3.67 \\
Age level & 37.33 & 38.07 & 32.76 \\
Hourly wage rate & 9.16 & 8.82 & 8.00 \\
& & & \\
Household & & & \\
& & & \\
\#-children 0/3 & & & \\
\#-children 4/11 & 0.29 & 0.27 & 0.27 \\
\#-children 12/15 & 0.44 & 0.58 & 0.88 \\
\#-children 16/25 & 0.23 & 0.38 & 0.35 \\
\#-children 25 plus & 0.16 & 0.42 & 0.32 \\
Family size & 0.01 & 0.03 & 0.01 \\
Weekly Household income & 1.13 & 1.68 & 1.84 \\
N & 637.83 & 615.44 & 522.46 \\
\hline \hline & & & \\
\hline
\end{tabular}


Table 4: Parameter estimates for $\alpha$

\begin{tabular}{|c|c|c|c|c|}
\hline \multirow{2}{*}{ Dutch } & \multicolumn{2}{|c|}{ Male } & \multicolumn{2}{|c|}{ Female } \\
\hline & Estimate & $z$-value & Estimate & $z$-value \\
\hline leisure & 0.752 & 66.00 & 0.759 & 50.55 \\
\hline household work & 0.005 & 4.19 & -0.003 & -2.35 \\
\hline household production $(H)$ & -0.010 & -0.59 & 0.066 & 3.15 \\
\hline$H$ interaction term & -0.001 & -0.04 & 0.084 & 2.86 \\
\hline household income & 0.223 & 10.61 & 0.095 & 4.63 \\
\hline job working hours & 0.031 & 3.44 & -0.001 & -0.15 \\
\hline \multirow[t]{2}{*}{ Surinamese/Antillean } & \multicolumn{2}{|c|}{ Male } & \multicolumn{2}{|c|}{ Female } \\
\hline & Estimate & $z$-value & Estimate & $z$-value \\
\hline leisure & 0.841 & 62.72 & 0.681 & 63.47 \\
\hline household work & 0.006 & 5.97 & -0.014 & -10.13 \\
\hline household production $(H)$ & -0.053 & -0.56 & 0.133 & 1.37 \\
\hline$H$ interaction term & -0.140 & -1.55 & 0.167 & 1.84 \\
\hline household income & 0.299 & 8.61 & 0.009 & 0.28 \\
\hline job working hours & 0.048 & 3.85 & 0.024 & 3.5 \\
\hline \multirow[t]{2}{*}{ Turkish } & \multicolumn{2}{|c|}{ Male } & \multicolumn{2}{|c|}{ Female } \\
\hline & Estimate & $z$-value & Estimate & $z$-value \\
\hline leisure & 0.924 & 64.82 & 0.499 & 34.08 \\
\hline household work & 0.019 & 8.12 & -0.009 & -6.4 \\
\hline household production $(H)$ & -0.095 & -1.78 & 0.205 & 3.11 \\
\hline$H$ interaction term & -0.107 & -1.90 & 0.180 & 2.57 \\
\hline household income & 0.115 & 4.36 & 0.133 & 5.64 \\
\hline \multirow[t]{2}{*}{ job working hours } & 0.144 & 13.69 & -0.009 & -3.79 \\
\hline & Dutch & Sur./Ant. & Turkish & \\
\hline $\bar{\pi}_{n}$ & 0.549 & 0.473 & 0.523 & \\
\hline$\zeta$ & 0.975 & 1.35 & 0.8 & \\
\hline $\mathrm{N}$ & 153 & 113 & 91 & \\
\hline
\end{tabular}




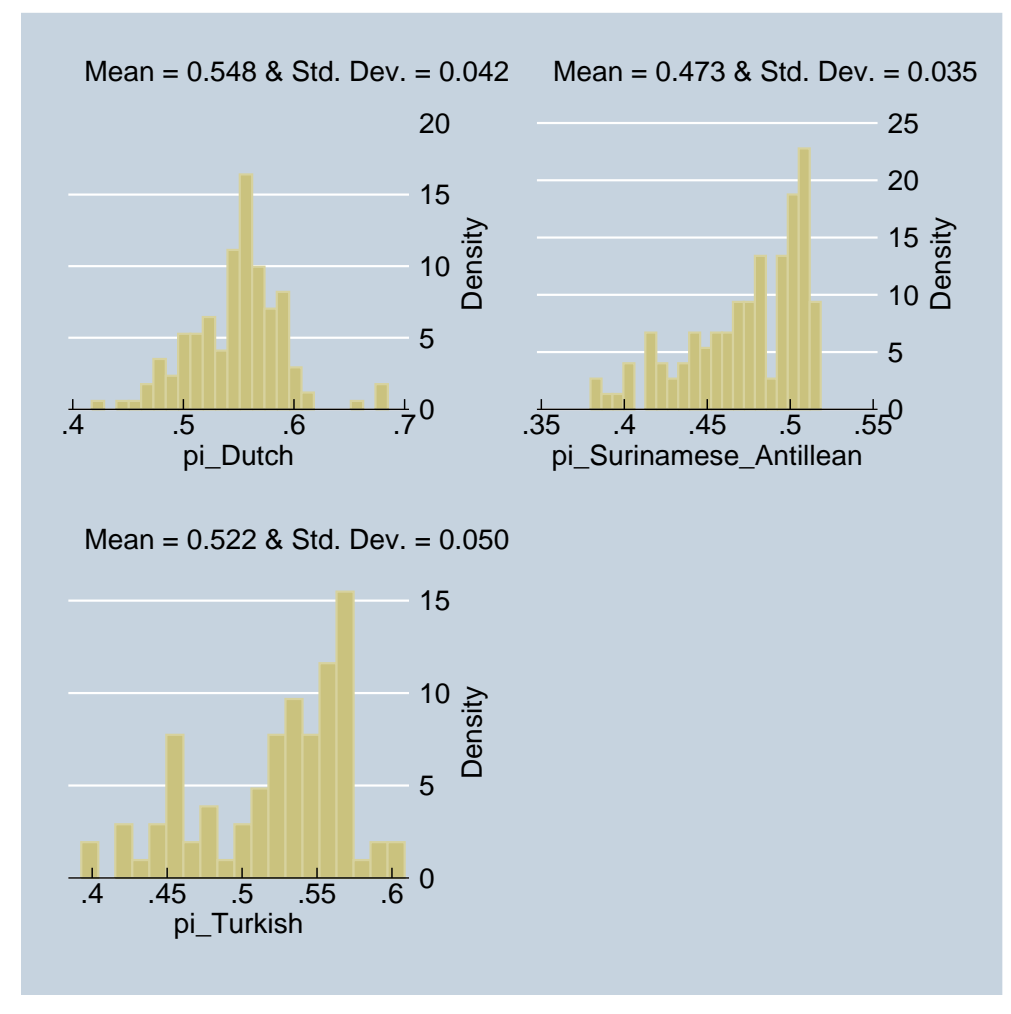

Figure 1: Distribution graphs of $\pi_{n}$ for the different alternatives 
Table 5: Estimates of the Power Function $\pi_{n}$

\begin{tabular}{|c|c|c|c|c|}
\hline & \multicolumn{2}{|c|}{ Dutch } & \multicolumn{2}{|c|}{ Sur./Ant. } \\
\hline & Estimate & z-value & Estimate & z-value \\
\hline $\log \left(w_{\text {male }}\right)$ & $0.174^{* * *}$ & 3.20 & 0.011 & 0.40 \\
\hline $\log \left(w_{\text {female }}\right)$ & $-0.190^{* * *}$ & -3.96 & 0.029 & 0.94 \\
\hline $\log (\#$-children $0 / 3+1)$ & $-0.185^{* * *}$ & -3.87 & $-0.222^{* * *}$ & -6.91 \\
\hline $\log (\#$-children $4 / 11+1)$ & 0.033 & 0.89 & $-0.089^{* * *}$ & -4.43 \\
\hline $\log (\#$-children $12 / 15+1)$ & 0.001 & 0.02 & $-0.043^{* *}$ & -2.04 \\
\hline $\log (\#$-children $>16+1)$ & -0.073 & -1.22 & 0.030 & 1.36 \\
\hline $\log \left(a g e_{\text {male }}\right)$ & $0.445^{* * *}$ & 2.92 & 0.050 & 0.57 \\
\hline $\log \left(\right.$ age $\left._{\text {female }}\right)$ & $-0.402^{* *}$ & -2.62 & -0.082 & -0.89 \\
\hline $\mathrm{N}$ & 153 & & 113 & \\
\hline \multicolumn{5}{|c|}{ Turkish } \\
\hline & Estimate & z-value & & \\
\hline $\log \left(w_{\text {male }}\right)$ & $0.144^{* * *}$ & 4.2 & & \\
\hline $\log \left(w_{\text {female }}\right)$ & $-0.100^{* * *}$ & -3.88 & & \\
\hline $\log (\#$-children $0 / 3+1)$ & $-0.360^{* * *}$ & -8.38 & & \\
\hline $\log (\#$-children $4 / 11+1)$ & -0.007 & -0.27 & & \\
\hline $\log (\#$-children $12 / 16+1)$ & $-0.064^{* *}$ & -2.06 & & \\
\hline $\log (\#$-children $>16+1)$ & $-0.099^{* * *}$ & -2.95 & & \\
\hline $\log \left(\right.$ age $\left._{\text {male }}\right)$ & -0.032 & -0.42 & & \\
\hline $\log \left(a g e_{\text {female }}\right)$ & 0.041 & 0.55 & & \\
\hline $\mathrm{N}$ & 91 & & & \\
\hline
\end{tabular}

Note: ${ }^{*}$ significant at $10 \%$ level, ${ }^{* *}$ significant at $5 \%$ level, ${ }^{* * *}$ significant at $1 \%$ level. 
Table 6: Average Wage Elasticities

\begin{tabular}{|c|c|c|c|c|}
\hline \multirow[b]{3}{*}{$l e_{m}$} & \multicolumn{2}{|c|}{ Dutch } & \multicolumn{2}{|c|}{ Sur./Ant. } \\
\hline & $\mathbf{w}_{m}$ & $\mathbf{w}_{f}$ & $\mathbf{w}_{m}$ & $\mathbf{w}_{f}$ \\
\hline & -0.15 & 0.15 & -0.02 & 0.12 \\
\hline$w h_{m}$ & -4.41 & 4.11 & -4.24 & 2.32 \\
\hline$j h_{m}$ & 1.16 & -1.10 & 1.08 & -0.85 \\
\hline$l e_{f}$ & 0.17 & -0.16 & 0.07 & -0.14 \\
\hline$w h_{f}$ & 2.63 & -2.60 & 2.51 & -1.24 \\
\hline \multirow[t]{3}{*}{$j h_{f}$} & -1.89 & 1.78 & -1.88 & 1.54 \\
\hline & \multicolumn{2}{|c|}{ Turkish } & & \\
\hline & $\mathbf{w}_{m}$ & $\mathbf{w}_{f}$ & & \\
\hline$l e_{m}$ & -0.02 & 0.06 & & \\
\hline$w h_{m}$ & -1.46 & 1.26 & & \\
\hline$j h_{m}$ & 0.53 & -0.57 & & \\
\hline$l e_{f}$ & 0.23 & -0.26 & & \\
\hline$w h_{f}$ & 0.38 & -0.48 & & \\
\hline$j h_{f}$ & -1.31 & 1.75 & & \\
\hline
\end{tabular}


Table 7: Child Effects

\begin{tabular}{lrrrr}
\hline \hline Dutch & & & & \\
& $\mathbf{C}_{0}^{3}$ & $\mathbf{C}_{4}^{11}$ & $\mathbf{C}_{12}^{15}$ & $\mathbf{C}_{16}^{+}$ \\
$l e_{m}$ & -0.027 & -0.004 & -0.002 & -0.006 \\
$w h_{m}$ & 0.097 & -0.022 & -0.091 & -0.027 \\
$j h_{m}$ & 0.054 & 0.019 & 0.043 & 0.024 \\
$l e_{f}$ & 0.010 & -0.019 & -0.008 & 0.001 \\
$w h_{f}$ & 0.098 & 0.210 & 0.301 & 0.117 \\
$j h_{f}$ & -0.208 & -0.109 & -0.157 & -0.173 \\
& & & & \\
Sur./Ant. & & & & \\
& $\mathbf{C}_{0}^{3}$ & $\mathbf{C}_{4}^{11}$ & $\mathbf{C}_{12}^{15}$ & $\mathbf{C}_{16}^{+}$ \\
$l e_{m}$ & -0.036 & -0.030 & 0.003 & 0.008 \\
$w h_{m}$ & 0.284 & 0.326 & -0.263 & -0.169 \\
$j h_{m}$ & -0.026 & -0.018 & 0.049 & 0.006 \\
$l e_{f}$ & 0.006 & -0.003 & -0.017 & -0.012 \\
$w h_{f}$ & 0.003 & 0.003 & 0.404 & 0.172 \\
$j h_{f}$ & -0.060 & -0.072 & -0.128 & -0.032 \\
& & & & \\
Turkish & & & & \\
& $\mathbf{C}_{0}^{3}$ & $\mathbf{C}_{4}^{11}$ & $\mathbf{C}_{12}^{15}$ & $\mathbf{C}_{16}^{+}$ \\
$l e_{m}$ & -0.051 & -0.007 & -0.009 & -0.007 \\
$w h_{m}$ & 0.141 & -0.005 & -0.017 & -0.081 \\
$j h_{m}$ & 0.025 & 0.012 & 0.040 & 0.047 \\
$l e_{f}$ & 0.012 & -0.030 & -0.011 & -0.010 \\
$w h_{f}$ & 0.091 & 0.330 & 0.283 & 0.423 \\
$j h_{f}$ & -0.236 & -0.045 & -0.211 & -0.192 \\
& & & & \\
\hline \hline & & & & \\
\hline
\end{tabular}

